\title{
Development and characterization of tri- and tetra-nucleotide polymorphic microsatellite markers for skipjack tuna (Katsuwonus pelamis)
}

\author{
Sudath T. Dammannagoda*, Vincent Chand and Peter B. Mather \\ Biogeosciences Discipline, Faculty of Science and Engineering, Queensland University of Technology, \\ GPO Box 2434, Brisbane, QLD 4001, Australia. \\ Accepted 20 April 2012
}

\begin{abstract}
Skipjack tuna (SJT), Katsuwonus pelamis is the largest tuna fishery in all the major oceans around the world, and the largest marine fishery in Sri Lanka. Knowledge of genetic population structure and effective population size of SJT in the Indian Ocean and other major oceans, however, is still lacking for improved management practices and conservation strategies. We developed microsatellite genetic markers using SJT found around Sri Lanka in the Indian Ocean, and characterized one tri- and seven tetra-nucleotide microsatellite loci isolated from enriched genomic libraries from SJT, to provide tools for addressing both conservation and fisheries management strategies. Analysis of these eight microsatellite markers in two populations of SJT from eastern Sri Lanka $(n=44)$ and the Maldives Islands $(n=53)$ showed that all eight microsatellites were polymorphic with an average number of alleles per locus of 11.80 (range 5-27). Expected heterozygosities at marker loci ranged from 0.450 to 0.961 . No significant linkage disequilibrium was detected among any loci pairs. These markers are currently being used to characterize population structure and extent of natural gene flow in SJT populations from the eastern and western Indian Ocean.
\end{abstract}

Key words: genetic diversity, population structure, Sri Lanka, Indian Ocean

\section{INTRODUCTION}

Skipjack tuna (SJT), Katsuwonus pelamis (Linnaeus, 1758), is widely distributed across all major oceans across the globe and constitute a major food commodity both regionally and internationally. In addition, though not widely recognized, SJT constitutes the largest tuna fishery worldwide. In 2009, global SJT catch had reached 2,599,681 metric tonnes (mt), and comprised $42 \%$ of the total global tuna catch (FAO, 2011). Based on life history characteristics and fishery data SJT are currently considered, like most tuna species, to constitute a single reproductive unit and hence are managed essentially as a single stock in all oceans around the world by the respective international commissions (i.e. IOTC-Indian Ocean Tuna Commission; WCPFC-Western and Central Pacific Fisheries Commission; IATTCInter-American Tropical Tuna Commission; and ICCAT-International Commission for the Conservation of Atlantic Tuna). Recent studies of SJT using both mitochondrial DNA (mtDNA) and nuclear DNA (nDNA) microsatellite markers however, detected two divergent mtDNA clades and fine-scale geographical population structure in the northwestern Indian Ocean (Dammannagoda et al., 2011). Information on population structure of SJT in the wild will be critical for conservation management efforts, but highly sensitive genetic markers are essential for determining structure of wild stock as SJT have a capacity to disperse long distances and wild populations are still at large in some regions.

Although SJT comprise the largest tuna fishery in the world, only a few genetic studies have been conducted to assess the structure of their wild stock and studies have mainly concentrated in the Pacific and Atlantic Oceans. A population genetic study of SJT carried out at an oceanic scale in the Atlantic and Pacific Oceans that employed mtDNA RFLP (Restriction Fragment Length Polymorphism) data could not detect any differentiation between Atlantic and Pacific Ocean populations (Graves et al., 1984), or from the Atlantic and Indian Oceans (Ely et al., 2005). Another study on population structure of SJT could differentiate samples from India and Japan using mtDNA RFLP markers (Menezes et al., 2005); it failed, however, to differentiate the Japanese sample and a SJT sample from the western coast of

\footnotetext{
*Corresponding author's email: s.dammannagoda@qut.edu.au
} 
India using microsatellite markers (Menezes et al., 2008).

Microsatellites commonly provide hypervariable markers that can provide the sensitivity necessary to detect even weak population structure where it exists. Although several studies have developed and characterized microsatellite markers for tuna species (e.g. Atlantic bluefin tuna; Broughton and Gold, 1997; Takagi et al., 1999; McDowell et al., 2002; Clark et al., 2004), there has been only a single report of microsatellite primers developed for SJT (Menezes et al., 2008), and they only reported on development of dinucleotide markers. Dinucleotide microsatellite markers frequently suffer from stutter bands that are more prone to genotype scoring errors than equivalent tri- and tetranucleotide repeat loci (McDowell et al., 2002). Scoring problems associated with dinucleotide markers can be particularly problematic when relatively large numbers of alleles are present at marker loci, in addition to the large sample sizes that are often required to adequately estimate allele frequencies. In the current study, we focused our attention on developing tri- and tetranucleotide microsatellite markers for SJT because in general, they should result in fewer problems with stutter bands and they commonly have fewer number of alleles per locus than comparable dinucleotide repeat microsatellites. Tri- and tetranucleotide microsatellites, however, are much less abundant in the nDNA genome compared to dinucleotide microsatellites (Toth et al., 2000), making development of tri- and tetranucleotide microsatellites a difficult task.

\section{MATERIALS AND METHODS}

\section{Genomic library development}

A single tri- and seven tetranucleotide microsatellite markers were developed for SJT after generating a microsatellite library using a radio-isotopic method (Chand et al., 2005) at the molecular genetics laboratory, Queensland University of Technology, Brisbane, Australia. Genomic DNA was extracted from SJT samples that were collected around Sri Lanka using a salt

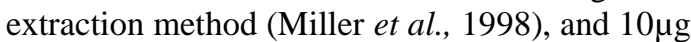
of DNA was digested with DpnII (5' GATC 3') and Sau3A I (3' CTAG 5'). Digested, purified DNA (300-700 bp) was ligated to a plasmid vector pUC 18 Bam I/BAP (Amersham Pharmacia Biotech). Ligated DNA with the vector was transferred to $E$. coli competent cells using heat shock. Competent cells with ligated DNA were then cultured on LB/AMP/XGal/IPTG plates, and positive clones were identified. Colonies with positive clones were transferred to Hybond $^{+}$nylon membranes and DNA was fixed and hybridized with a mixture of radioactive labeling oligo-nucleotide probes $(\mathrm{CAC})_{8},(\mathrm{CAG})_{8},(\mathrm{GACA})_{6},(\mathrm{GATA})_{6}$.

Clones with microsatellite inserts were identified by exposing hybridized membranes on X-ray film. Positive clones were selected from the plates, and grown in Terrific Broth/Ampicillin 50mg/ml (TB/Amp) solution. DNA was then extracted from grown out positive clones using a miniprep protocol (QIAGEN - www.qiagen.com). RNAase treated positive clones were sequenced using M13F primer (5' GTA AAA CGA CGG CCA GT '3) at the "Australian Genome Research Facility" (AGRF) (Brisbane, Australia) and checked for microsatellite repeats discarding short repeats and duplicated clones. Primers were designed using the PRIMER3 software (Rozen and Skaletsky, 2000).

\section{Primer design, optimisation and screening of populations}

Approximately 200 positive SJT clones were identified of which 80 were randomly sequenced. Based on sequence analyses, 17 unique primer pairs were designed and evaluated for polymorphism. Clone sequences were deposited in GenBank with accession numbers HM631812-HM631828 (Table 1). Of the 17 primer pairs screened, 10 primer pairs produced reliable microsatellite products. Of these 10 loci, two could not be scored unambiguously due to amplification of spurious bands. The remaining eight loci were polymorphic and considered to be suitable for screening variation in SJT populations (Table 2). Suitability of these eight microsatellite markers to detect genetic variation of SJT populations was assessed by screening 44 individuals from a single site in the east of Sri Lanka (Kalmunei - KM), and 53 individuals from the Maldive Islands (Male - MD) as a remote group. The PCR reaction mix consisted of $\sim 50 \mathrm{ng} / \mu \mathrm{l}$ DNA $1 \mu \mathrm{l}, 1.25 \mu \mathrm{l}$ of $10 \mathrm{X}$ PCR buffer (Roche), $0.25 \mu \mathrm{l}$ of $25 \mathrm{mM} \mathrm{MgCl}_{2}, 0.5 \mu \mathrm{l}$ of $10 \mathrm{mM}$ dNTP (Roche), $0.5 \mu \mathrm{l}$ of each $10 \mathrm{mM}$ forward and reverse primers, $0.1 \mu \mathrm{l}$ of Taq (Roche) and $\mathrm{ddH}_{2} \mathrm{O}$ to a final volume of $10 \mu \mathrm{l}$. Forward primers were labelled with Hexa fluorescent dye (GeneWorks, Hindmarsh, SA, Australia) for visualisation. Amplification consisted of an initial denaturation of 4 minutes at $95{ }^{\circ} \mathrm{C}$, then 29 cycles of (i) $95{ }^{\circ} \mathrm{C}$ for $30 \mathrm{sec}$, (ii) at appropriate annealing temperature (Table 1) for $30 \mathrm{sec}$, (iii) $72{ }^{0} \mathrm{C}$ for $30 \mathrm{sec}$; and a final extension step at $72{ }^{0} \mathrm{C}$ for $8 \mathrm{~min}$. PCR products were electrophoresed in $0.6 \mathrm{X}$ TBE $6 \%$ 
acrylamide gels (100 $\mu \mathrm{m}$ thick) on a GS2000 Genetic Analyser (Corbett Research). According to the Corbett manual, with a 50-350 bp sizing standard (Tamra-T350) to determine allele size. Resulting products were scored using OneDscan software (Scanalytics Inc.). Summary data for the 17 microsatellite loci developed are presented in Table 1.

\section{Statistical analysis}

Raw microsatellite data were summarised into allele frequencies for each locus at the two sampling sites using the software CONVERT (Glaubitz, 2004). This software was also used to transform data into other data formats for subsequent analyses using other statistical software packages. Microsatellite data were checked for presence of null alleles, large allele dropout and errors in scoring using Microchecker software version 2.2.3 (Oosterhout et al., 2004). Conformance of genotypic frequencies at each locus to Hardy-Weinberg equilibrium (HWE) expectations was estimated with Arlequin version 3.5.1.3 (Schneider et al. 2005), with significance of deviations in observed vs. expected heterozygosity tested using Exact tests (Guo and Thompson, 1992). The possibility of linkage disequilibrium (LD) among loci was investigated using the method of Slatkin and Excoffier (1996) in Arlequin with 1000 permutations $(\alpha=0.05) . P$ values were adjusted using the Bonferroni correction (Rice, 1989). Measures of genetic variation and descriptive statistics for two populations including number of alleles $\left(N_{A}\right)$, allelic richness $(A R)$, and inbreeding coefficient $\left(F_{\text {is }}\right)$ were calculated using the software program FSTAT version 2.9.3.2 (Goudet, 1995). To enable comparison of diversity across sites, allelic richness $(A R)$ was calculated for each locus at both sites (in addition to number of alleles), which corrects for different sample sizes using rare faction (Leberg, 2002).

\section{RESULTS}

Measures of genetic variation and descriptive statistics for two populations are summarised in Table 2. All loci that amplified successfully were polymorphic possessing 5 to 27 alleles, respectively. Four loci (UTD172, UTD328, UTD523 and UTD531) from sampling site MD showed significant deviations from HWE after Bonferroni correction (Rice, 1989) for multiple tests. Three of the four loci showing HWE deviations (except UTD 535) indicated a possibility of null alleles being present due to excess of homozygotes, after analysis with MICROCHECKER (Oosterhout et al., 2004). In addition, locus 328 at site KM also showed possibility of null alleles due to excess of homozygotes. Linkage disequilibrium was not detected between any pairs of loci after Bonferroni correction.

\section{DISCUSSION}

The single tri- and seven tetranucleotide microsatellite markers optimised here show a high level of polymorphism, according to number of alleles and allelic richness at each locus and at both sampling sites (Table 2). Most importantly, these tri- and tetranucleotide microsatellite markers, compared to dinucleotides, display a low level of stutter bands. Further, stutter bands in di-nucleotide microsatellite markers can easily and frequently cause scoring errors if the two alleles are closely spaced (Perlin et al., 1995).

Six of these eight microsatellite markers have been used successfully for screening over 333 individuals from nine sampling sites around Sri Lanka, the Laccadive Islands, and the Maldive Islands to characterise population structure and extent of natural gene flow in SJT populations from the north western Indian Ocean (Dammannagoda et al., 2011). In addition, these markers are being used currently to screen SJT populations from the eastern Indian Ocean around Malaysia (Bhassu, S. pers.comm.).

In this analysis, deviations from HWE at some loci had been expected however, as the populations screened here comprised of individuals from two divergent SJT mtDNA clades (Dammannagoda et al., 2011), potentially causing a Wahlund effect as indicated by excess of homozygotes at these loci (Chand et al., 2005). Of the 17 primer pairs developed in this study, only 8 could be optimised to a condition that is suitable for large scale screening of individuals, due to time and funding constrains. The seven tetranucleotide and the single trinucleotide polymorphic microsatellite loci described here provide a powerful addition to the markers already available for SJT. They will also contribute to development of a better understanding of the scale of individual dispersal, population structure within and between wild SJT populations, effective population sizes of each clade for the conservation and management of wild stocks, and for investigating evolutionary processes underlying genetic divergence among populations across major global oceans. 
Table 1. Summary data for 17 developed SJT (Katsuwonus pelamis) microsatellite loci.

\begin{tabular}{|c|c|c|c|c|c|c|c|}
\hline Locus & Repeat motiff & & Primer sequence (5'-3') & Product size (bp) & Size range & $\mathbf{T}_{\mathrm{a}}{ }^{0} \mathrm{C}$ & $\begin{array}{c}\text { GenBank } \\
\text { accession } \\
\text { number }\end{array}$ \\
\hline \multirow[t]{2}{*}{ UTD535 } & $(\mathrm{AGAT})_{9}$ & $\mathrm{~F}$ & CAC TGA AGA TAT AGG CAG CCT TG & 193 & $(150-218)$ & 55 & HM631826 \\
\hline & & $\mathrm{R}$ & TTT CTC CAG CGG CAT TAC AT & & & & \\
\hline \multirow[t]{2}{*}{ UTD523 } & $(\text { GATA })_{18}$ & $\mathrm{~F}$ & TTT GAA TGG GAG ACA TGC AG & 247 & $(172-268)$ & 55 & HM631818 \\
\hline & & $\mathrm{R}$ & TGT CCT GCA CTT GTG TTC ACT & & & & \\
\hline \multirow[t]{2}{*}{ UTD172 } & $(\mathrm{GACT})_{5}$ & $\mathrm{~F}$ & GTT GTG TAT TTT TGG CTG GAC C & 145 & $(118-158)$ & 55 & HM631813 \\
\hline & & $\mathrm{R}$ & CAA CAG CTA ACG GGC AAA TTC C & & & & \\
\hline \multirow[t]{2}{*}{ UTD328 } & $(\mathrm{GCT})_{8}$ & $\mathrm{~F}$ & GAG AGA GAA GCG GAC AGG ATA GG & 143 & $(120-157)$ & 50 & HM631815 \\
\hline & & $\mathrm{R}$ & TGA GTA ATA GAG AGT GGG AAT GG & & & & \\
\hline \multirow[t]{2}{*}{ UTD203 } & $(\mathrm{GAA})_{7} \mathrm{CT}(\mathrm{GAA})_{2}$ & $\mathrm{~F}$ & CCC TGT GCT GTC TGT GAA G & 157 & $(134-161)$ & 50 & HM631814 \\
\hline & & $\mathrm{R}$ & TTG AAT CAA TGG CAA CTG GA & & & & \\
\hline \multirow[t]{2}{*}{ UTD73 } & $(\mathrm{AACT})_{6}$ & $\mathrm{~F}$ & TGT GTG ATG AAG CTA AAG & 135 & $(148-188)$ & 50 & HM631828 \\
\hline & & $\mathrm{R}$ & CAA AAA TAT AGC CTT CGT & & & & \\
\hline \multirow[t]{2}{*}{ UTD329 } & $(\mathrm{AACT})_{7}$ & $\mathrm{~F}$ & TAC TGG GTG ATG AAG CTA AAG AC & 146 & $(136-172)$ & 55 & HM631816 \\
\hline & & $\mathrm{R}$ & TCG TAA GGG AAT ATA AAA AAG TG & & & & \\
\hline \multirow[t]{2}{*}{ UTD531 } & $(\mathrm{ATCT})_{16}$ & $\mathrm{~F}$ & GCA GTC CTG TGG GTG ATT AAA & 201 & $(198-246)$ & 55 & HM631823 \\
\hline & & $\mathrm{R}$ & $\begin{array}{l}\text { GGT AAG TAT CAG AGG CTC TAC CAT } \\
\text { C }\end{array}$ & & & & \\
\hline \multirow[t]{2}{*}{ UTD149 } & $(\mathrm{GGA})_{11}$ & $\mathrm{~F}$ & ACC GGT GGC TTG AAG ATT GAC AG & 262 & na & 56 & HM631812 \\
\hline & & $\mathrm{R}$ & GTA AAG CTC TCT СТC СТC TCC CT & & & & \\
\hline
\end{tabular}




\begin{tabular}{|c|c|c|c|c|c|c|c|}
\hline \multirow[t]{2}{*}{ UTD 522} & $(\mathrm{GATA})_{17}$ & $\mathrm{~F}$ & GATTATGTTCAGTGTTCCAAGCTC & 389 & na & 58 & HM631817 \\
\hline & & $\mathrm{R}$ & CACAGACAGGAAAGCAATCA & & & & \\
\hline \multirow[t]{2}{*}{ UTD526 } & $(\mathrm{GATA})_{28}$ & $\mathrm{~F}$ & $\begin{array}{l}\text { GCT CTA AAT TAA ATG GAG CAT CAA } \\
\text { A }\end{array}$ & 245 & na & 52 & HM631819 \\
\hline & & $\mathrm{R}$ & GCA GAA TCC AGT CTA GTG CAA A & & & & \\
\hline \multirow[t]{2}{*}{ UTD528 } & $(\mathrm{CTAT})_{11}$ & $\mathrm{~F}$ & GGC CTA GCT AGC AGA ATC ACT C & 150 & na & 54 & HM631820 \\
\hline & & $\mathrm{R}$ & AGT GCC ATT GAA CCC ACC TA & & & & \\
\hline \multirow[t]{2}{*}{ UTD529 } & $(\mathrm{GACA})_{4}$ GACGA $(\mathrm{ATAG})_{22}$ & $\mathrm{~F}$ & ACCCAGCAATTGACATCTGA & 245 & na & 58 & HM631821 \\
\hline & & $\mathrm{R}$ & ACTAATGAATTCGCGGCC & & & & \\
\hline \multirow[t]{2}{*}{ UTD530 } & $(\text { TAGA })_{14}$ TATA $(\text { TAGA })_{5}$ & $\mathrm{~F}$ & GTT TAA GGC CTA GCT AGC AGA A & 188 & na & 52 & HM631822 \\
\hline & & $\mathrm{R}$ & TCC CCG AGA GTG AAA ATG TC & & & & \\
\hline \multirow[t]{2}{*}{ UTD532 } & $(\mathrm{TATC})_{21}$ & $\mathrm{~F}$ & GGC CTA GCT AGC AGA ATC CA & 190 & na & 52 & HM631824 \\
\hline & & $\mathrm{R}$ & TGC TGC CAT TAT ACC TGC AT & & & & \\
\hline \multirow[t]{2}{*}{ UTD533 } & $(\mathrm{CTAT})_{12}$ & $\mathrm{~F}$ & ACGCGTCAGACTGCACTTC & 225 & na & 60 & HM631825 \\
\hline & & $\mathrm{R}$ & GCACATATTACGGTAAATACACCG & & & & \\
\hline \multirow[t]{2}{*}{ UTD540 } & $(\mathrm{ATAG})_{17}$ & $\mathrm{~F}$ & TCA TCC TCT CCA TTG AAC CTC & 236 & na & 53 & HM631827 \\
\hline & & $\mathrm{R}$ & GGC CTA GCT AGC AGA ATC ACA & & & & \\
\hline
\end{tabular}


Table 2. Descriptive statistics for two SJT (Katsuwonus pelamis) populations for eight microsatellite loci. (Significant probability values after Bonferroni correction: $\alpha=0.05 / 16=0.0031)$.

\begin{tabular}{|c|c|c|c|c|c|c|c|c|c|c|}
\hline \multirow[b]{2}{*}{ Population } & & \multirow[b]{2}{*}{ UTD535 } & \multirow[b]{2}{*}{ UTD523 } & \multicolumn{4}{|c|}{ Locus } & \multirow[b]{2}{*}{ UTD329 } & \multirow[b]{2}{*}{ UTD531 } & \multirow[b]{2}{*}{ Avg. across loci } \\
\hline & & & & UTD172 & UTD328 & UTD203 & UTD73 & & & \\
\hline \multirow[t]{4}{*}{$\mathbf{K M}$} & $N$ & 37 & 33 & 34 & 43 & 44 & 40 & 31 & 25 & 35.875 \\
\hline & $N_{A}$ & 14 & 19 & 7 & 9 & 5 & 8 & 7 & 12 & 10.125 \\
\hline & $\mathrm{H}_{\mathrm{E}}$ & 0.914 & 0.925 & 0.676 & 0.820 & 0.471 & 0.688 & 0.625 & 0.918 & 0.755 \\
\hline & $F$ is & 0.115 & 0.051 & -0.356 & 0.179 & -0.308 & 0.02 & 0.072 & 0.131 & 0.016 \\
\hline \multirow[t]{3}{*}{ MD } & $N$ & 41 & 43 & 45 & 51 & 53 & 51 & 48 & 39 & 46.375 \\
\hline & $N_{A}$ & 16 & 27 & 10 & 12 & 7 & 11 & 11 & 14 & 13.500 \\
\hline & $F$ is & 0.175 & $0.422 *$ & $-0.131^{*}$ & $0.224 *$ & -0.006 & 0.047 & 0.124 & $0.551 *$ & 0.200 \\
\hline
\end{tabular}




\section{REFERENCES}

Broughton, R.E. and Gold, J.R. (1997). Microsatellite development and survey of variation in northern bluefin tuna (Thunnus thynnus). Molecular Marine Biology and Biotechnology 6:308-314.

Chand,V., De Bruyn, M. and Mather, P.B. (2005). Microsatellite loci in the eastern form of the giant freshwater prawn (Macrobrachium rosenbergii). Molecular Ecology Notes 5:308-310.

Clark, T.B., Ma, L., Saillant, E., and Gold, J.R. (2004). Microsatellite DNA markers for population-genetic studies of Atlantic bluefin tuna (Thunnus thynnus thynnus) and other species of genus Thunnus. Molecular Ecology Notes 4:70-74.

Dammannagoda, S.T., Hurwood, D.A. and Mather, P.B. (2011). Genetic analysis reveals two stocks of skipjack tuna (Katsuwonus pelamis) in the north western Indian Ocean. Canadian Journal of Fisheries and Aquatic Sciences 68(2): 210-223.

Ely, B., Vinas, J., Alvarado Bremer, J., Black, B., Lucas, L., Covello, K., Labrie, A.V. and Thelen, E. (2005). Consequences of the historical demography in the global population structure of two highly migratory cosmopolitan marine fishes: the yellowfin tuna (Thunnus albacares) and skipjack tuna (Katsuwonus pelamis). BMC Evolutionary Biology 5:19.

FAO (2011). FAO fishery statistical collections: Global tuna nominal catches-online query. http://www.fao.org/fishery/statistics/tunacatches. Accessed 20 Feb 2011.

Glaubitz, J.C. (2004). CONVERT: A userfriendly program to reformat diploid genetic data for commonly use population genetics software packages. Molecular Ecology Notes 4:309-310.

Goudet, J. (1995). FSTAT (Version 1.2): a computer program to calculate F-statistics. Heredity 86: 485-486.

Graves J.E., Ferris S.D. and Dizon, A.E. (1984). High genetic similarity of Atlantic and Pacific skipjack tuna demonstrated with restriction endonuclease analysis of mitochondrial DNA. Marine Biology 79:315319.

Guo, S. and Thompson, E. (1992). Performing the exact test of Hardy-Weinberg proportion for multiple alleles. Biometrics. 48:361-372.

Leberg, P.L. (2002). Estimating allelic richness: effects of sample size and bottlenecks. Molecular Ecology 11: 2445-2447.
McDowell, J.R., Diaz-Jaimes, P. and Graves, J.E. (2002). Isolation and characterization of seven tetranucleotide microsatellite loci from Atlantic northern bluefin tuna Thunnus thynnus thynnus. Molecular Ecology Notes 2: 214-216.

Menezes, M.R., Ikeda, M. and Taniguchi, N. (2005). Genetic variation in skipjack tuna Katsuwonus pelamis (L.) using PCR-RFLP analysis of the mtDNA D-loop region. Journal of Fish Biology 68: Supplement A, 156-161.

Menezes, M.R., Noguchi, D., Nakajima, M. and Taniguchi, M. (2008). Microsatellite development and survey of genetic variation in skipjack tuna Katsuwonus pelamis. Journal of Fish Biology 73:463-473.

Miller, S.A., Dykes, D.D. and Polesky, H.F. (1988). A simple salting out procedure for extracting DNA from nucleated cells. Nucleic Acid Research 16:1215.

Oosterhout, C., Hutchinson, W.F., Wills, P.M.D. and Shipley, P. (2004). Microchecker: software for identifying and correcting genotyping errors in microsatellite data. Molecular Ecology Notes 4: 535-538.

Perlin, M.W., Lancia, G. and Ng, S.K. (1995). Towards fully automated genotyping: genotyping microsatellite markers by deconvolution. American Journal of Human Genetics 57:1199-2210.

Rice, W.J. (1989). Analysing tables of statistical tests. Evolution 43: 223-225.

Rozen, S. and Skaetsky, H. (2000). Primer3 on the WWW for General Users and for Biologist Programmers. In: Stephen, M. and Stephen A. K. (Eds) Bioinformatics Methods and Protocols, Humana Press, MA, UK 132: 365-386.

Schneider, S., Roesslli, D. and Excoffier, L. (2005). Arlerquin version 2.00: a software for population genetics data analysis.

Slatkin, M. and Excoffier, L. (1996). Testing for linkage disequilibrium in genotypic data using the expectation-maximization algorithm. Heredity. 76: 377-383.

Takagi, M., Okamura, T., Chow, S. and Taniguch, N. (1999). PCR primers for microsatellite loci in tuna species of the genus Thunnus and its application for population genetic study. Fisheries Science 65:571-576.

Toth, G., T., Zoltan G., and Jerzy J. (2000). Microsatellites in Different Eukaryotic Genomes: Survey and Analysis. Genome Research 10: 967-981. 